\title{
Self-Assembly of Elastin-Mimetic Double Hydrophobic Polypeptides
}

Duc H. T. Le, ${ }^{\dagger}$ Ryo Hanamura, ${ }^{\dagger}$ Dieu-Huong Pham, ${ }^{\dagger}$ Masaru Kato, ${ }^{\ddagger}$ David A. Tirrell, ${ }^{\S}$ Tatsuya Okubo, $^{\dagger}$ and Ayae Sugawara-Narutaki* ${ }^{\dagger}$

${ }^{\dagger}$ Department of Chemical System Engineering, The University of Tokyo, 7-3-1 Hongo, Bunkyo-ku, Tokyo 113-8656, Japan

${ }^{\ddagger}$ Graduate School of Pharmaceutical Sciences and Global COE Program, The University of Tokyo, 7-3-1 Hongo, Bunkyo-ku, Tokyo 113-0033, Japan

${ }^{\S}$ Division of Chemistry and Chemical Engineering, Joseph J. Jacobs Institute for Molecular Engineering for Medicine, California Institute of Technology, Pasadena California 91125, United States

\section{Supporting Information}

ABSTRACT: We have constructed a novel class of "doublehydrophobic" block polypeptides based on the hydrophobic domains found in native elastin, an extracellular matrix protein responsible for the elasticity and resilience of tissues. The block polypeptides comprise proline-rich poly(VPGXG) and glycinerich poly(VGGVG), both of which dehydrate at higher temperature but form distinct secondary structures, $\beta$-turn and $\beta$-sheet respectively. In water at $45{ }^{\circ} \mathrm{C}$, the block polypeptides initially assemble into nanoparticles rich in $\beta$ turn structures, which further connect into long $(>10 \mu \mathrm{m})$,

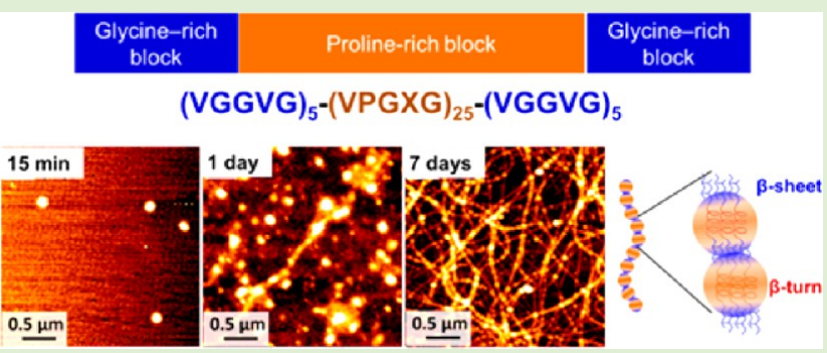
beaded nanofibers along with the increase in the $\beta$-sheet content. The nanofibers obtained are well-dispersed in water, and show thermoresponsive properties. Polypeptides comprising each block component assemble into different morphologies, showing that the conjugation of poly(VPGXG) and poly(VGGVG) plays a role for beaded fiber formation. These results may provide innovative ideas for designing peptide-based materials but also opportunities for developing novel materials useful for tissue engineering and drug delivery systems.

\section{INTRODUCTION}

Elastin is an extracellular matrix protein that provides connective tissues with elastic extensibility and recoil. ${ }^{1}$ In vivo, elastin is assembled and cross-linked to form elastic fibers from its soluble precursor tropoelastin, ${ }^{2,3}$ a $72 \mathrm{kDa}$ protein with a high proportion of hydrophobic residues arranged in repeated motifs. ${ }^{4}$ It is well-accepted that the hydrophobic domains of tropoelastin are essential for its self-assembly processes. ${ }^{5}$ These are classified into two basic types: proline-rich domains, with VPGXG (X = any amino acid except $\mathrm{P}$ ) repeated motifs, and glycine-rich domains, with YGG and YGGZG (Y, Z = L, V, or A) repeated motifs, located at the center and at both termini of tropoelastin, respectively (Figure 1a). ${ }^{6,7}$ Studies by Tamburro et al. show that some proline-rich segments behave similarly to tropoelastin; they undergo a reversible, temperature-induced coacervation, which is a critical step for the self-assembly process of tropoelastin, through dehydration and rehydration of the hydrophobic side chains. ${ }^{8}$ By contrast, isolated glycine-rich domains also show temperature-dependent dehydration, but irreversibly assemble to form amyloid-like fibers. ${ }^{9-11}$ The function of the glycine-rich domains remains unclear. One hypothesis is that they are uniquely important for the selfassembly and mechanical properties of elastin, owing to their intrinsic tendency to form $\beta$-sheets to produce rigid structures. $^{12}$ a)

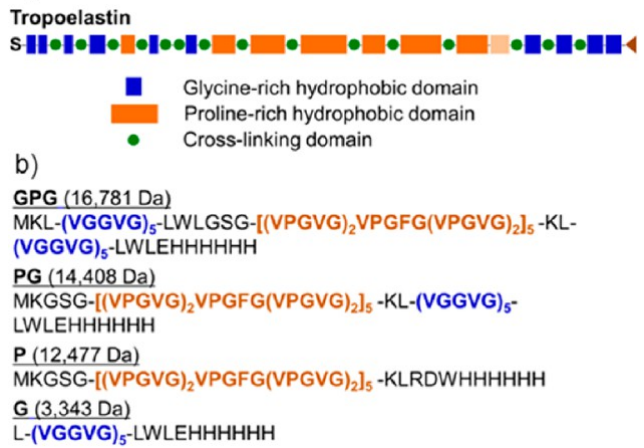

Figure 1. (a) Domain structure encoded by the human tropoelastin gene. Reprinted with permission from Tamburro, A. M.; Bochicchio, B.; Pepe, A. Biochemistry 2003, 42, 13347-13362. Copyright 2003 American Chemical Society. (b) Amino acid sequences of constructed polypeptides.

Tailor-made elastin-like polypeptides (ELPs) that mimic the motifs of tropoelastin inherit the remarkable elasticity and selfassembly properties of the parent protein. Thus, they are

Received: December 10, 2012

Revised: February 27, 2013

Published: March 18, 2013 
promising for use in tissue engineering, ${ }^{13-15}$ as drug delivery systems, ${ }^{16-18}$ and as biological tools. ${ }^{19,20}$ For example, various ELPs consisting of proline-rich sequences (VPGXG), where X is a guest amino acid residue except proline, have been prepared and used as stimulus-responsive materials. ${ }^{21}$ The coacervation temperatures $T_{\mathrm{t}}$ can be precisely tuned by guest residue composition, molecular weight, and ELP concentration. $^{22}$ Introducing a charged residue such as lysine provides ELPs with $\mathrm{pH}$-responsive properties ${ }^{23}$ and cross-linkable sites. $^{24,25}$ Thin films and hydrogels obtained from ELPs have been examined as bioelastic materials for tissue regeneration. $^{14,15}$ Amphiphilic ELP block copolymers with different temperature responses between the two blocks have also been synthesized; they form nanoparticles of various sizes at temperature above $T_{\mathrm{t}}$ and have been proposed for use as drug delivery carriers. ${ }^{18}$ Chaikof et al. have synthesized series of triblock copolymers in which the hydrophilic elastomeric middle block is flanked by hydrophobic plastic blocks. ${ }^{26}$ Hydrogels assembled from these block copolymers exhibit controlled mechanical properties depending on the relative lengths of the elastomeric and plastic blocks. ${ }^{29}$ Another method to functionalize ELPs is fusing the flexible segments (GVGVP) with rigid silk-like segments (GAGAGS) to take advantage of both the high tensile strength derived from silk and the resilience derived from elastin. ${ }^{28}$ In contrast, there has been limited research on glycine-rich ELPs. Synthetic (XGGVG) polymers ( $\mathrm{X}=\mathrm{V}$ or $\mathrm{L}, \bar{m}=5$ or 7 , respectively) exhibit strong tendencies to assemble into amyloid-like fibers in water, similar to the isolated glycine-rich domain of tropoelastin. ${ }^{29,30}$ Keeley et al. constructed a series of ELPs consisting of several domains of tropoelastin and noted that the combined proportion of proline and glycine residues was a critical factor for promoting their self-assembly into elastic fibers or amyloid fibers. ${ }^{31}$ However, the localization of each domain was not taken into account.

Here we report a novel "double-hydrophobic" class of ELP block copolymers comprising both proline-rich and glycine-rich sequences, which are designed on the basis of the nonuniform distribution of domains in tropoelastin (Figure 1). The selfassembly behaviors of the block polypeptides and each component segments are studied in detail by using circular dichroism (CD) spectroscopy and atomic force microscopy (AFM) to elucidate how the conjugation between proline-rich and glycine-rich sequences influences on the self-assembly. The block polypeptides assemble into beaded nanofibers with considerable flexibility and homogeneity at high temperature while each component block shows different assembly pathways. The beaded nanofibers obtained are well-dispersed in water, and they show temperature-responsive properties. These characteristics make the nanofibers promising candidates for use as components of biomimetic scaffolds in tissue engineering or as carriers in drug delivery systems.

\section{MATERIALS AND METHODS}

Plasmids Construction. All cloning procedures were carried out in the Escherichia coli strain SURE (Stratagene). Gene sequences were verified by restriction mapping and DNA sequencing analysis. The expression vectors used in this study are illustrated in Figure 2: pET$22 \mathrm{~b}(+)-\mathbf{P} ;$ pET-22b(+)-PG; and pET-22b(+)-GPG. First, a gene fragment encoding the proline-rich sequence [(VPGVG) $)_{2}$ VPGFG$\left.(\mathrm{VPGVG})_{2}\right]_{5}$ (P) from a pQE60-derived plasmid that contained the original $\mathbf{P}$ gene, ${ }^{19}$ was amplified by the polymerase chain reaction (PCR). The PCR amplification modified the $3^{\prime}$ end of the $\mathbf{P}$ gene by introducing a $6 \times$ histidine tag, a stop codon, and a BamHI restriction
pET-22b(+)-P

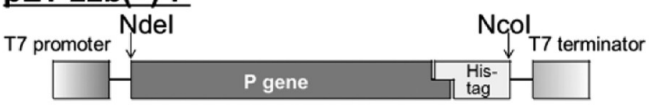

pET-22b(+)-PG

T7 promoter
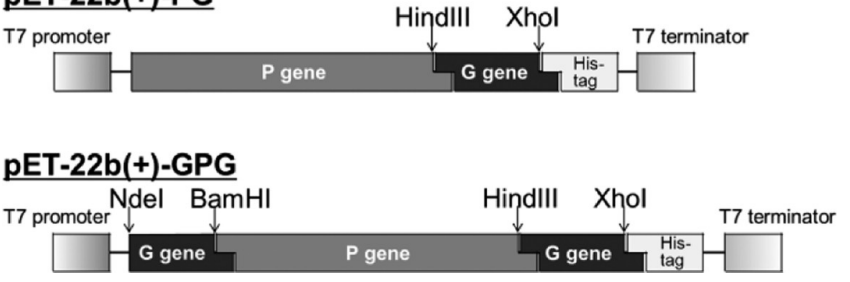

Figure 2. Detailed schematics of the constructed expression vectors.

site. The PCR product was isolated by BamHI digestion, and then inserted into pQE60 at the BamHI site to yield a new plasmid encoding $\mathbf{P}$ with $\mathrm{His}$ tag. The $\mathbf{P}$ with His tag gene region was further PCR-amplified and outfitted with $\mathrm{NdeI}$ and $\mathrm{NcoI}$ restriction sites at its $3^{\prime}$ and $5^{\prime}$ ends, respectively. The final PCR product was excised by double digestion with $\mathrm{NdeI}$ and $\mathrm{NcoI}$ and then ligated between the NdeI and NcoI sites of pET-22b(+) (Novagen) to give pET-22b(+)-P.

A synthetic DNA fragment encoding $(\mathrm{VGGVG})_{5}(\mathbf{G})$ with HindIII and XhoI restriction sites at its $3^{\prime}$ and $5^{\prime}$ ends, respectively, was obtained from Integrated DNA Technologies. This G gene was isolated by double digestion with HindIII and XhoI and ligated between the HindIII and XhoI sites of pET-22b(+)-P to give pET$22 \mathrm{~b}(+)$-PG. Another G gene was PCR-amplified from the synthetic DNA fragment encoding G. In the amplification step, an NdeI site was introduced at the $3^{\prime}$ end and the $\mathrm{XhoI}$ site was replaced by a BamHI site at the $5^{\prime}$ end. The PCR product was double digested with NdeI and $B a m H I$ and inserted between the corresponding sites of pET$22 \mathrm{~b}(+)$-PG to yield pET-22b(+)-GPG. These constructs were each transformed into the E. coli BLR(DE3) strain, which is suitable for expressing recombinant proteins with repeating motifs. ${ }^{32}$

Polypeptide Expression and Purification. A single colony was used to inoculate $5 \mathrm{~mL}$ of Luria-Bertani (LB) medium with ampicillin $(200 \mathrm{mg} / \mathrm{L})$ and the culture was incubated overnight at $37^{\circ} \mathrm{C}$. The culture was then added to a flask containing $1 \mathrm{~L}$ sterilized Terrific Broth (TB) medium (12 g bacto tryptone, $24 \mathrm{~g}$ yeast extract, and 4 $\mathrm{mL}$ glycerol in $1 \mathrm{~L}$ sterilized deionized water) with ampicillin (200 $\mathrm{mg} / \mathrm{L}$ ). L-Proline (Wako, first grade) was added to a final concentration of $100 \mathrm{mM}$ to replenish the intracellular amino acid pool. The $\mathrm{pH}$ of the TB medium was maintained around 7.0-7.2 by adding potassium hydrogen phosphate $(12.54 \mathrm{~g})$ and potassium dihydrogen phosphate $(2.31 \mathrm{~g})$. Bacterial cultures were incubated at 37 ${ }^{\circ} \mathrm{C}$ for $12 \mathrm{~h}$ with agitation $(200 \mathrm{rpm})$. E. coli cells were harvested by centrifugation $\left(4000 \mathrm{rpm}, 4{ }^{\circ} \mathrm{C}, 30 \mathrm{~min}\right)$, redispersed in lysis buffer $(8$ $\mathrm{M}$ urea, $100 \mathrm{mM}$ sodium hydrogen phosphate, and $10 \mathrm{mM}$ 2-amino-2hydroxymethyl-propane-1,3-diol; $\mathrm{pH} 8.0$ ) and kept at $-80^{\circ} \mathrm{C}$. Frozen samples were subsequently freeze-thawed and subjected to sonication. Cell lysates were collected after eliminating insoluble substances by centrifugation $\left(20000 \mathrm{rpm}, 4{ }^{\circ} \mathrm{C}, 30 \mathrm{~min}\right)$. Subsequently, $5 \mathrm{~mL}$ of Ni-nitrilotriacetate (Ni-NTA) agarose resin (Qiagen) was added and mixed for $1 \mathrm{~h}$ at room temperature to allow binding of the His tag to Ni-NTA. The resin suspension was then applied to a column and washed with $8 \mathrm{M}$ urea $(\mathrm{pH}$ 6.3). Target polypeptides were eluted with $8 \mathrm{M}$ urea $(\mathrm{pH} 4.5)$ and collected in plastic tubes. The collected fractions were dialyzed against distilled water in a $4{ }^{\circ} \mathrm{C}$ chamber. The insoluble fractions generated during dialysis were removed with a $0.2 \mu \mathrm{m}$ filter. The supernatant was lyophilized to yield the final product in the form of a powder. Purification for the polypeptides was confirmed by matrix-assisted laser desorption ionization-time of flight mass spectroscopy (MALDI-TOFMS) and sodium dodecyl sulfate polyacrylamide gel electrophoresis (SDS-PAGE).

Preparation of G Polypeptide. $\mathbf{G}$ was obtained by digesting the diblock polypeptide PG with trypsin (Sigma-Aldrich, Proteomic 
grade), which cleaves the chain at the lysine residue between the $\mathbf{P}$ and G sequences. The enzyme to substrate ratio was adjusted to 1:100 in $100 \mathrm{mM}$ urea buffer $(\mathrm{pH} \mathrm{8.0)}$ to minimize undesirable aggregation. The reaction was conducted at $37^{\circ} \mathrm{C}$ for $18 \mathrm{~h}$. Because the target polypeptide contained the His tag, it was purified using a Ni-NTA column. MALDI-TOF-MS was used to confirm the purity of the polypeptide.

Sample Preparation. Block polypeptides were stored in the form of lyophilized powders at $-20{ }^{\circ} \mathrm{C}$. To make stock solutions, the protein powder was dissolved in cool deionized water and agitated in a $4{ }^{\circ} \mathrm{C}$ chamber. The concentrations of dissolved polypeptides were determined with a NanoDrop 1000 Spectrophotometer (Thermo Scientific). Milli-Q water was added to make the final polypeptide concentration $20 \mu \mathrm{M}$. During these experiments, sample solutions were kept on ice to prevent undesirable aggregation of the polypeptides.

Turbidity Measurement. The temperature-dependent turbidity profile of the GPG suspension $(20 \mu \mathrm{M})$ was monitored by using a UV-visible spectrometer (JASCO V-670) equipped with a temperature controller. The absorbance was measured at $350 \mathrm{~nm}$ from 16 to $45{ }^{\circ} \mathrm{C}$ at a heating rate of $1{ }^{\circ} \mathrm{C} \mathrm{min}^{-1}$ without stirring.

Circular Dichroism (CD) Spectroscopy. CD spectra were acquired with a JASCO J-820 Spectrometer under constant nitrogen flush and using a standard rectangular quartz cell of $0.1 \mathrm{~cm}$ path length. A total of 10 scans were obtained over the wavelength range of $195-260 \mathrm{~nm}$ at the experimental temperatures $\left(16\right.$ and $45^{\circ} \mathrm{C}$ ) by acquiring points every $0.1 \mathrm{~nm}$ using a scan speed of $50 \mathrm{~nm} / \mathrm{min}$, an integration time of $2 \mathrm{~s}$, and a bandwidth of $1 \mathrm{~nm}$. Before these measurements, samples were equilibrated for $5 \mathrm{~min}$. The final spectra were obtained after subtracting the spectrum of the blank solvent. The data are expressed as mean residue molar ellipticity $[\theta]$, which was calculated as follows: ellipticity/path length $(\mathrm{cm}) \times$ concentration $(\mathrm{mol} / \mathrm{L}) \times$ number of residues $\times 10$.

Atomic Force Microscopy (AFM). Samples were dropped onto freshly cleaved mica substrates, which had been preincubated at 16 or $45{ }^{\circ} \mathrm{C}$. The samples were dried at the temperatures used for selfassembly $\left(16\right.$ or $45{ }^{\circ} \mathrm{C}$ ). Assembled structures were imaged on a Nanowizard II Microscope (JPK Instruments). Observations were made in intermittent contact mode at a scan rate between 0.2 and 1.5 $\mathrm{Hz}$ using $\mathrm{Si}$ cantilevers in air and at room temperature.

Scanning Electron Microscopy (SEM). Lyophilized samples of GPG suspension that had been incubated at 45 or $16{ }^{\circ} \mathrm{C}$ were attached to substrates using carbon paste. SEM images were taken with a Hitachi S-900 at an accelerating voltage of $6 \mathrm{kV}$. To enhance surface conductivity, the samples were sputter-coated with $\mathrm{Pt}$ in an argon atmosphere prior to observation.

Transmission Electron Microscopy (TEM). A suspension of $\mathbf{G}$ $(3 \mu \mathrm{L})$ that had been incubated at $45^{\circ} \mathrm{C}$ for 7 days was dropped on a hydrophilized collodion-coated copper grid. The sample was negatively stained with $3 \mu \mathrm{L}$ of $2 \%$ phosphotungstic acid solution ( $\mathrm{pH}$ 7.2), and then dried under air. Observation was performed with a JEOL 2000EX at an accelerating voltage of $200 \mathrm{kV}$.

\section{RESULTS AND DISCUSSION}

Design of Block Polypeptides. An ELP block copolymer, in which glycine-rich sequences $(\mathrm{VGGVG})_{5}$ were fused at both ends of a proline-rich sequence $\left[(\mathrm{VPGVG})_{2}(\mathrm{VPGFG})\right.$ $\left.(\mathrm{VPGVG})_{2}\right]_{5}$, was constructed and designated GPG (Figure 1b). A diblock counterpart, PG, in which $(\mathrm{VGGVG})_{5}$ was attached at the C-terminus of the proline-rich sequence, was also synthesized, as VGGXG repeats are more abundant at the C-terminus in tropoelastin. ${ }^{10,33} \mathrm{~A}$ phenylalanine $(\mathrm{F})$ residue at the fourth position of every fifth VPGVG unit controls the thermoresponsive properties of these polypeptides. ${ }^{34}$ Polypeptides containing each component block were also prepared and designated $\mathbf{P}$ and $\mathbf{G}$, respectively. All polypeptides incorporated oligohistidine tags (His tags) for purification. The yields of GPG, PG and $\mathbf{P}$ from $1 \mathrm{~L}$ cell culture were about $10 \mathrm{mg} / \mathrm{L}$.
Purified polypeptides were analyzed by SDS-PAGE and MALDI-TOF-MS (Figure 3). On the other hand, a pET-

a)

\begin{tabular}{ccc}
\hline $\begin{array}{c}\text { Constructed } \\
\text { Polypeptides }\end{array}$ & $\begin{array}{c}\text { Calculated } \\
\mathbf{M}_{\mathrm{w}}(\mathrm{Da})\end{array}$ & $\begin{array}{c}\text { MS identified } \\
\mathbf{M}_{\mathrm{w}}(\mathrm{Da})\end{array}$ \\
\hline GPG & 16,781 & 16,786 \\
PG & 14,408 & 14,411 \\
P & 12,477 & 12,477 \\
G & 3,343 & 3,345 \\
\hline
\end{tabular}

b)

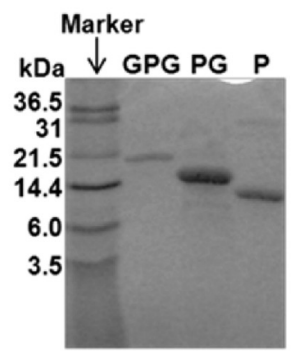

c)

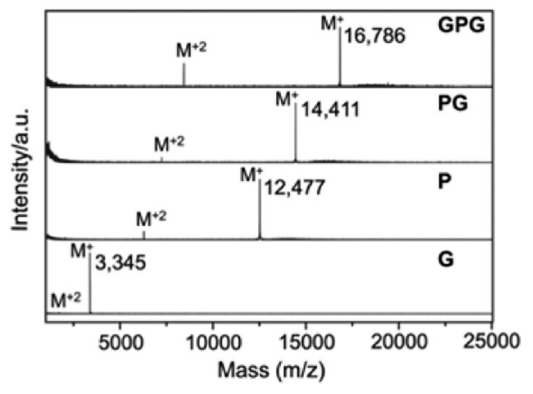

Figure 3. (a) Molecular weight $\left(M_{\mathrm{w}}\right)$ of constructed polypeptides. (b) SDS-PAGE (15\% tris-tricine gel) of polypeptides GPG, PG, and P. (c) MALDI-TOF-MS spectra of polypeptides GPG, PG, P, and G.

$22 \mathrm{~b}(+)$ plasmid encoding the $\mathbf{G}$ sequence was also successfully constructed, but the yield of $\mathbf{G}$ was low because the polypeptide coprecipitated with impurity proteins during dialysis. Therefore, $\mathbf{G}$ was obtained by cleaving $\mathbf{P}$ sequence from the diblock PG by using trypsin. The polypeptide was purified by using $\mathrm{Ni}$ NTA column as the His tag was remained after cleavage. The MALDI-TOF-MS spectrum of $\mathbf{G}$ after purification shown in Figure $3 c$ confirms the successful reaction. Analysis by SDSPAGE was also performed; however, there was no band observed, possibly due to inefficient binding of coomassie dyes to short peptides containing uncharged residues (data not shown).

Self-Assembly of the Triblock Polypeptide into Nanofibers. The thermoresponsive properties of GPG (20 $\mu \mathrm{M})$ were examined by measuring temperature-dependent changes in the turbidity of its solution. The absorbance at 350 $\mathrm{nm}$ was monitored from 16 to $45^{\circ} \mathrm{C}$ at a heating rate of $1{ }^{\circ} \mathrm{C}$ $\min ^{-1}$ (Figure 4). Although the turbidity profile did not display a typical phase transition with an abrupt increase in turbidity commonly observed for ELPs in salt solutions, ${ }^{21}$ a continuous

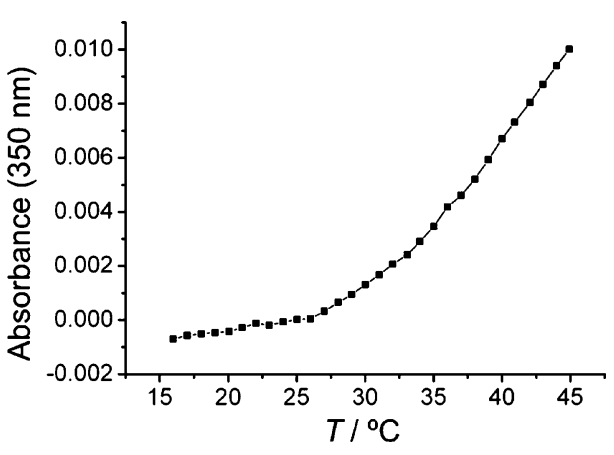

Figure 4. Turbidity profile of GPG $(20 \mu \mathrm{M})$ in water. 
a)

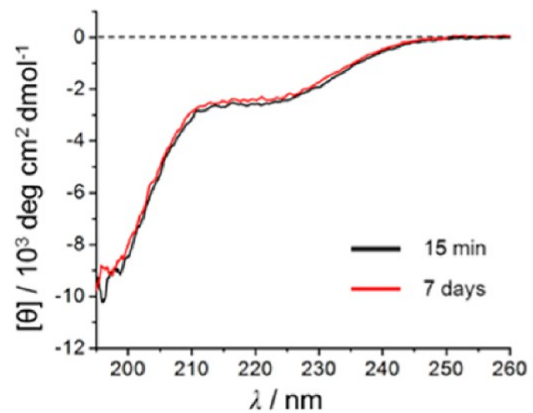

b)

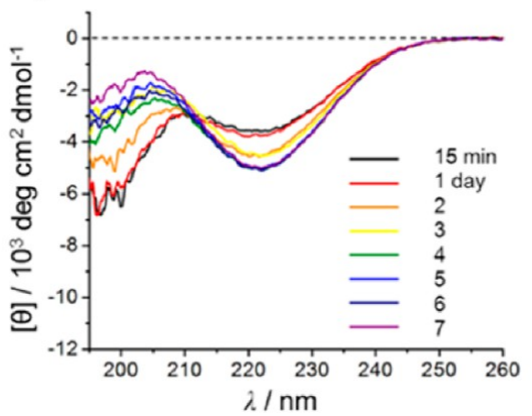

c)

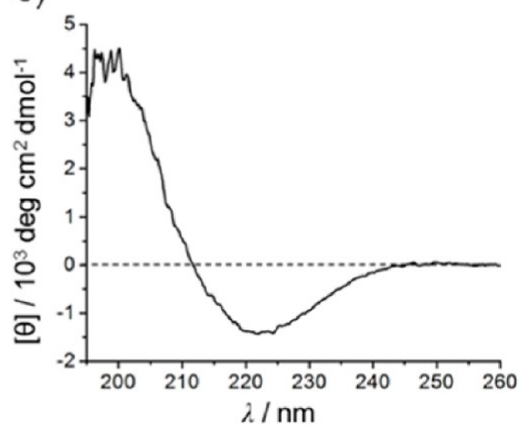

Figure 5. CD spectra of GPG at (a) $16{ }^{\circ} \mathrm{C}$ and (b) $45^{\circ} \mathrm{C}$. (c) CD difference spectrum obtained by subtracting the spectrum at $15 \mathrm{~min}$ from that at 7 days in (b).
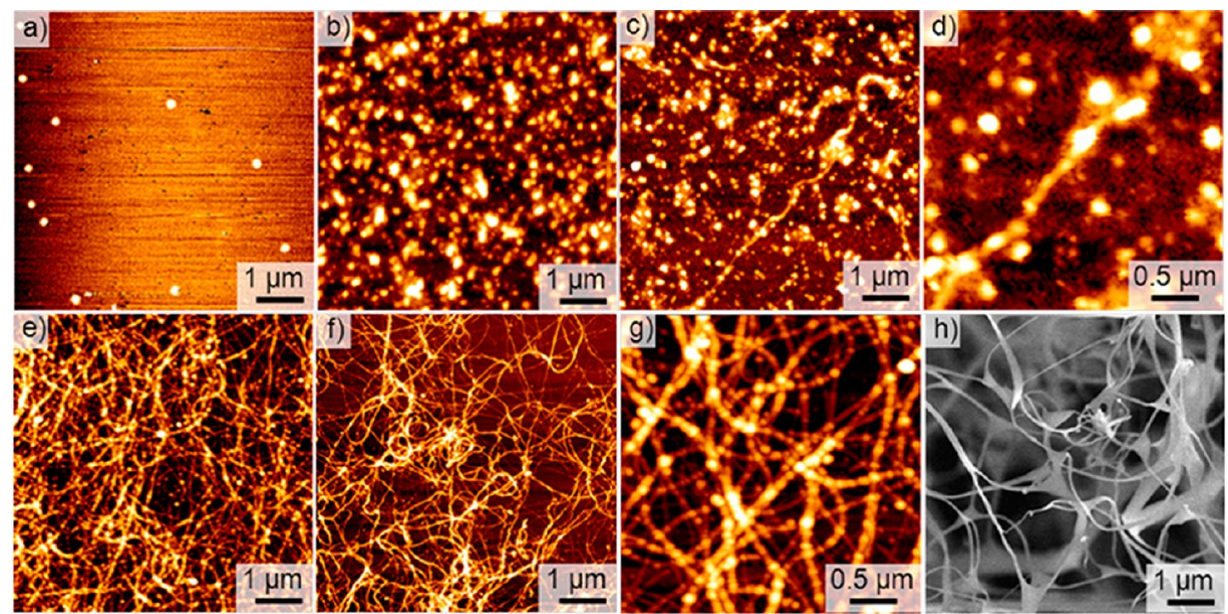

Figure 6. (a-g) AFM images of assembled structures of GPG formed at $45{ }^{\circ} \mathrm{C}$. (a) Particles formed just after preparation, (b) particles and (c) fibers formed after 1 day at different locations on the mica substrate, (d) high magnification image of a fiber formed after 1 day, (e) fibers formed after 2 days and (f) 7 days, and (g) high magnification image of nanofibers after 7 days. (h) SEM image of a freeze-dried sample after 7 days at $45^{\circ} \mathrm{C}$.

increase in turbidity over a wide temperature range was detected. This result indicates the assembly of GPG in response to a thermal trigger. The GPG solution turned visibly cloudy upon increasing the temperature without forming precipitates.

$\mathrm{CD}$ spectroscopy was used to study the associated changes in the secondary structure of GPG. At $16{ }^{\circ} \mathrm{C}$, an intense negative band around $200 \mathrm{~nm}$, with a negative shoulder at $224 \mathrm{~nm}$, was observed, indicating that GPG adopts a predominantly disordered structure that contains some $\beta$-turns (Figure 5a). The spectrum remained unchanged for 7 days at $16{ }^{\circ} \mathrm{C}$. In contrast, the CD spectrum of GPG showed evidence of structural change over 7 days at $45{ }^{\circ} \mathrm{C}$ (Figure 5b). The spectrum after $15 \mathrm{~min}$ of aging at $45{ }^{\circ} \mathrm{C}$ showed a reduced negative band at $200 \mathrm{~nm}$ and an increased negative band at 224 $\mathrm{nm}$ compared with the spectrum at $16{ }^{\circ} \mathrm{C}$. This observation suggests that the $\beta$-turn content of the polypeptide increases at the higher temperature, which is typical for ELPs. ${ }^{35}$ Timedependent spectra obtained over 7 days show progressive loss of intensity around $200 \mathrm{~nm}$ and growth in the intensity around $220 \mathrm{~nm}$. A CD difference spectrum (comparing samples at 15 min and at 7 days) highlights the nature of this transition; a strong positive peak around $200 \mathrm{~nm}$ and a negative peak at 220 $\mathrm{nm}$ signal the development of $\beta$-sheet structure with time (Figure 5c).

Figure $6 \mathrm{a}-\mathrm{g}$ shows the time-dependent morphological changes of GPG at $45{ }^{\circ} \mathrm{C}$ as observed by atomic force microscopy (AFM). Spherical particles 130-200 nm in diameter were observed immediately after increasing the temperature to $45{ }^{\circ} \mathrm{C}$ (Figure 6a). After 1 day, the particle density had increased significantly (Figure 6b). In addition, fibrils began to appear, as shown in Figure 6c. A magnified image reveals the beaded structures of the fibrils, which suggests that they were formed from precursor particles (Figure $6 \mathrm{~d})$. At day 2, virtually all the particles assembled into mature fibers (Figure 6e) and the morphologies remained unchanged after 7 days (Figure 6f). The mature fibers were about 20-70 $\mathrm{nm}$ in diameter and more than $10 \mu \mathrm{m}$ in length. Interestingly, it was frequently observed that these fibers were curled or coiled, behavior that suggests considerable flexibility. This morphology is different from either aligned filamentous fibers or amyloid fibers assembled from other reported ELPs. ${ }^{9,36}$ A closer look at the fibers confirms that they were composed of aligned particles (Figure $6 \mathrm{~g}$ ). Evidence from a scanning electron microscope (SEM) image of a lyophilized sample reveals that fiber formation occurred in water rather than during the drying process (Figure 6h), though the beaded structure was difficult to observe due to the deformation of fibers by electron beam at high magnification. No precipitation or gelation was observed for the GPG suspension even after prolonged aging (at least several weeks) at $45{ }^{\circ} \mathrm{C}$, showing the high dispersibility of the nanofibers.

The stability of the GPG fibers was tested by cooling fiber suspensions $\left(45^{\circ} \mathrm{C}, 7\right.$ days) to $16^{\circ} \mathrm{C}$. After $1 \mathrm{~h}$, AFM images showed isolated particles and short chains of particles in 
addition to some remaining fibers (Figure 7). Similar morphologies were observed in SEM images of lyophilized
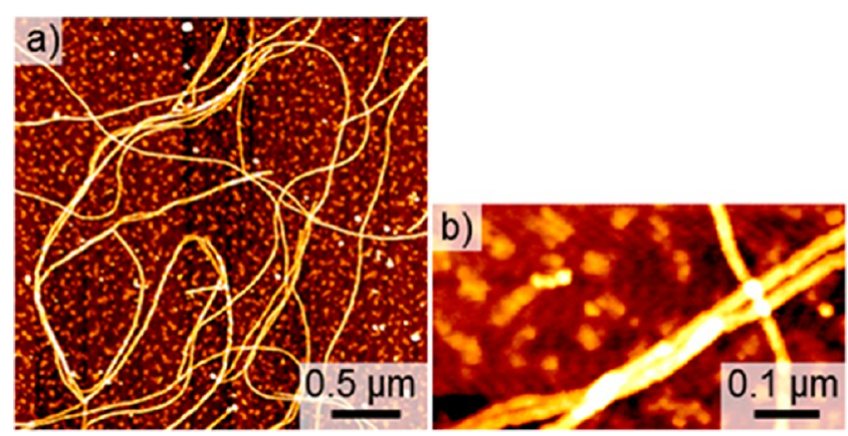

Figure 7. (a, b) AFM images of GPG fibers cooled to $16{ }^{\circ} \mathrm{C}$; (b) magnified image.

samples (Figure S1 in Supporting Information). However, the complete disappearance of fibers was not observed, even after $24 \mathrm{~h}$ of incubation at $16{ }^{\circ} \mathrm{C}$. These results indicate that fiber formation is at least partially reversible.

Self-Assembly of Control Polypeptides. Self-assembly of the control polypeptides (PG, P, and G) was also examined by $\mathrm{CD}$ and AFM. The diblock polypeptide PG initially assembled into nanoparticles, which are subsequently replaced by flexible nanofibers with an associated increase in $\beta$-sheet structure at 45 ${ }^{\circ} \mathrm{C}$ (Figure 8), indicating behavior similar to that of GPG nanofibers. However, the $\beta$-sheet content of PG-derived fibers was less than that of GPG fibers, as reflected by the weaker negative band at $220 \mathrm{~nm}$ in the $\mathrm{CD}$ spectrum after 7 days at 45 ${ }^{\circ} \mathrm{C}$ (Figure 8a), suggesting that the $\beta$-sheet conformation was characteristic of the $\mathbf{G}$ sequence (VGGVG) ${ }_{5}$. By contrast, each component block (i.e., the $\mathbf{P}$ and $\mathbf{G}$ polypeptides) behaves differently. $\mathbf{P}$ adopted primarily disordered conformations, together with some $\beta$-turns, in water at $16{ }^{\circ} \mathrm{C}$ (Figure 9a). The $\beta$-turn content increased upon increasing the temperature to 45 ${ }^{\circ} \mathrm{C}$, but no further change in the spectrum was observed for 7 days. The spectral change between 16 and $45{ }^{\circ} \mathrm{C}$ was reversible even after 7 days. The AFM images of $\mathbf{P}$ after $15 \mathrm{~min}$ and after 7 days of aging showed the presence of particles only (Figure $9 b, c)$. Taking the CD and AFM results together, we conclude that $\mathbf{P}$ assembles into particles rich in $\beta$-turn structures. In comparison to $\mathbf{P}, \mathbf{G}$ is more ordered at $16{ }^{\circ} \mathrm{C}$, as indicated by the reduced negative $\mathrm{CD}$ band at around $200 \mathrm{~nm}$ (Figure 10a). Upon increasing the temperature to $45{ }^{\circ} \mathrm{C}, \mathbf{G}$ rapidly forms $\beta$ sheet structures, as shown by a strong positive $\mathrm{CD}$ band near $195 \mathrm{~nm}$ and a negative band at $215 \mathrm{~nm}$ (Figure 10a), which were unchanged after 7 days. Amorphous aggregates consisting of fine primary particles were observed by AFM after $15 \mathrm{~min}$ and after 7 days of aging (Figure 10b,c). TEM observation revealed the fibrous nature of the particles; they are thin, short fibrils less than $5 \mathrm{~nm}$ in diameter (Figure 10d).

Hypothesis on the Fiber Formation. A tentative model for the formation of GPG fibers is proposed as shown in Figure 11. Upon heating, disordered chain structures are converted to $\beta$-turns, expelling bound water and increasing the entropy of the solvent. Polypeptide chains assemble through hydrophobic interactions, resulting in the formation of particles. GPG then rearranges within the particle to achieve the most thermodynamically stable state. Hydrophilic His tags induce the adjacent $(\text { VGGVG })_{5}$ segments to locate near the surface of the particle. These segments form intermolecular $\beta$-sheets that interdigitate as the particles assemble into fibers. Although mature fibers are already observed after 2 days, the continuing growth in the $\mathrm{CD}$ band at $220 \mathrm{~nm}$ suggests that (VGGVG) $)_{5}$ segments may form more $\beta$-sheet structure over time and stabilize connections between particles. The reduction in the diameter of the fibers $(20-70 \mathrm{~nm})$ as compared to the precursor particles (130-200 $\mathrm{nm}$ ) also suggests that the polypeptides arrange into more closely packed structures. The diblock polypeptide PG can also follow this scheme, given that the polypeptides align alternately one against another. It should be noted that this model shares some characteristics with elastogenesis, in which globular proteins assemble into beaded structures, in vivo and in vitro. ${ }^{37,38}$ Assemblies of synthetic short peptides into "beads on string" structures have also been reported. ${ }^{39,40}$ The wellcontrolled assembly of GPG, where assembly occurs in water in response to a temperature trigger, could provide further valuable insights into this phenomenon.

Conjugation of the (VPGXG) ${ }_{25}$ and $(\mathrm{VGGVG})_{5}$ domains is essential to fiber formation. $\mathbf{G}$ alone rapidly forms short fibrils at $45{ }^{\circ} \mathrm{C}$. The (VPGXG) ${ }_{25}$ domains in PG and GPG appear to act as barriers to this rapid formation. This effect is evident from the $\mathrm{CD}$ spectra (Figure $5 \mathrm{~b}$ ), which indicate only slow increases in $\beta$-sheet content during fiber assembly. Another indication of the interplay of the two domains is the partial reversibility of the fibers; we suggest that frustration of $\beta$-sheet assembly in PG and GPG enables disassembly of fibers upon cooling.

\section{CONCLUSIONS}

A novel class of elastin-like "double-hydrophobic" block polypeptides comprising proline-rich poly(VPGXG) and glycine-rich poly(VGGVG) segments have been constructed based on the unique domain structure of tropoelastin. The role a)

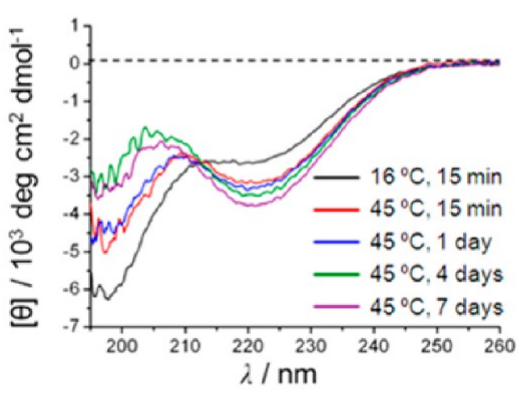

b)

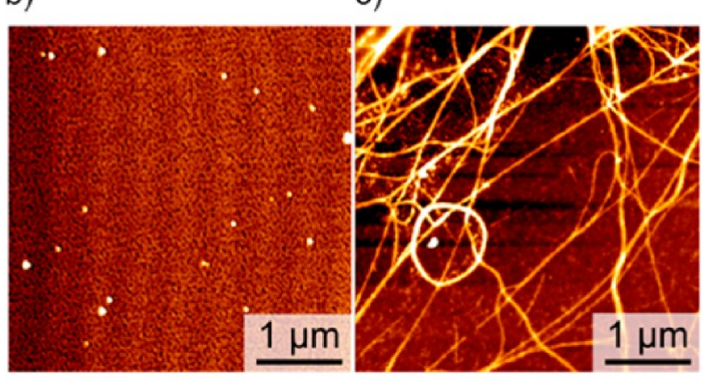

Figure 8. (a) CD spectra of PG at 16 and $45^{\circ} \mathrm{C}$. (b, c) AFM images of assembled structures of $\mathbf{P G}$ formed at $45^{\circ} \mathrm{C}$ after (b) 15 min and (c) 4 days. 
a)

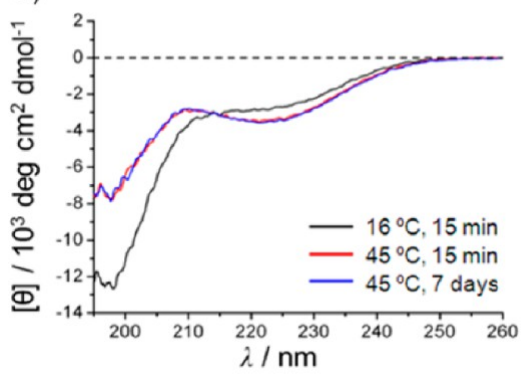

b)

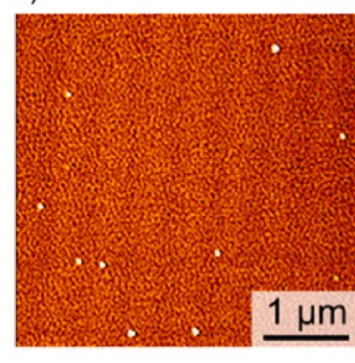

c)

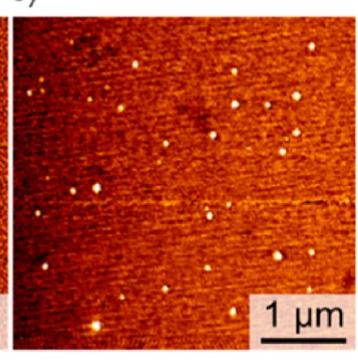

Figure 9. (a) CD spectra of $\mathbf{P}$ at 16 and $45{ }^{\circ} \mathrm{C}$. (b, c) AFM images of assembled structures of $\mathbf{P}$ formed at $45{ }^{\circ} \mathrm{C}$ after (b) 15 min and (c) 7 days.
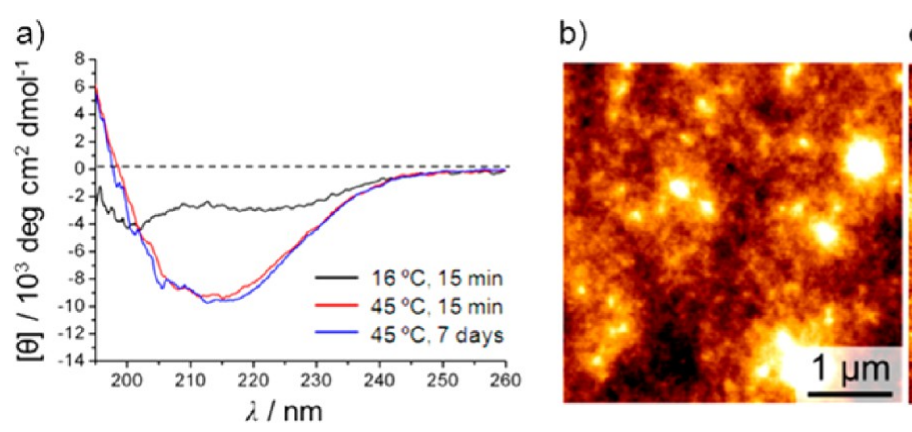

c)

d)

Figure 10. (a) $\mathrm{CD}$ spectra of $\mathbf{G}$ at 16 and $45^{\circ} \mathrm{C}$. (b, c) AFM images of assembled structures of $\mathbf{G}$ formed at $45^{\circ} \mathrm{C}$ after (b) 15 min and (c) 7 days. (d) TEM image of assembled structures of $\mathbf{G}$ formed at $45{ }^{\circ} \mathrm{C}$ after 7 days.

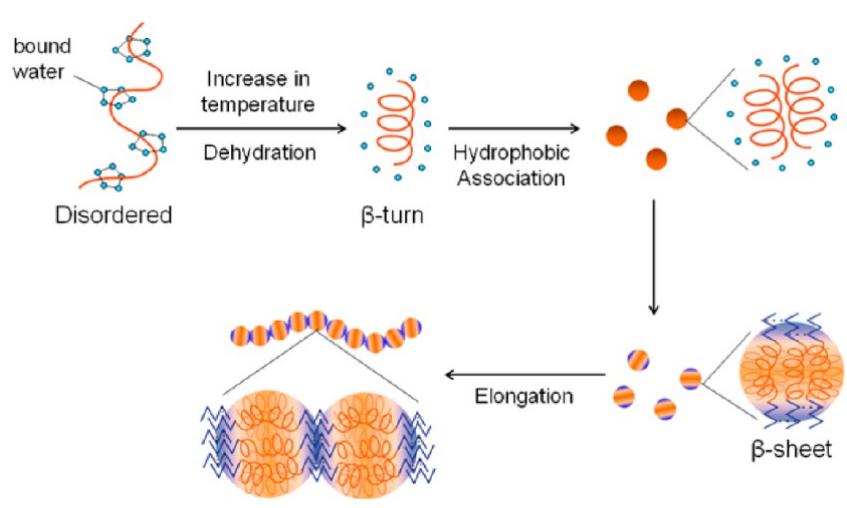

Figure 11. Tentative model for the assembly of GPG into nanofibers.

of the block structures in polypeptide self-assembly is proposed on the basis of detailed analysis of the assembly process and the comparative behavior of control polypeptides. In water at 45 ${ }^{\circ} \mathrm{C}$, the block polypeptides assemble initially into nanoparticles rich in $\beta$-turn conformation, which further connect into beaded nanofibers together with a slow increase in $\beta$-sheet content over 1 week. In contrast, control polypeptides comprising each block component [poly(VPGXG) or poly(VGGVG)] assemble into different morphologies, particles rich in $\beta$-turns or short fibrils of $\beta$-sheets, respectively, soon after increasing the temperature to $45{ }^{\circ} \mathrm{C}$. Unlike the block polypeptides, no further structure changes with time have been observed. The slow assembly of the poly(VGGVG) block into the $\beta$-sheet structure, which is restricted due to its linkage to the poly(VPGXG) block, may be important for the formation of beaded nanofibers. Tailor-made ELPs are of interest in modern nanotechnology and biotechnology owing to their sequence-dependent assembly and functional properties. Nevertheless, precise control of assembled structures and systematic understanding of the assembly processes of ELPs remain challenging. The double hydrophobic polypeptides reported here provide new principles for the design of ELPs and other peptide-based materials. Furthermore, the nanofibers obtained in this study, characterized by homogeneity and apparent flexibility, partial reversibility in response to temperature stimuli, and dispersal in water without precipitation, will be useful as components of scaffolds in tissue engineering and drug delivery systems.

\section{ASSOCIATED CONTENT}

\section{Supporting Information}

An SEM image of the lyophilized GPG fibers suspension when being reversely cooled from 45 to $16{ }^{\circ} \mathrm{C}$. This material is available free of charge via the Internet at http://pubs.acs.org.

\section{AUTHOR INFORMATION}

\section{Corresponding Author}

*Tel.: +81-3-5841-7368. Fax: +81-3-5800-3806. E-mail: ayae@ chemsys.t.u-tokyo.ac.jp.

\section{Notes}

The authors declare no competing financial interest.

\section{ACKNOWLEDGMENTS}

This work was supported by a Grant-in-Aid for Scientific Research (No. 22107005) on the Innovative Areas: "Fusion Materials" (Area No. 2206) from the Ministry of Education, Culture, Sports, Science and Technology (MEXT), Japan. D.H.T.L. is grateful to a Grant-in-Aid for Young Scientists from the Japan Society for the Promotion of Science (JSPS). A part of this work was conducted at the Center for Nanobio Integration (CNBI), Center for Medical System Integration (CMSI), and Center for Nano Lithography and Analysis, The University of Tokyo, supported by MEXT. We thank Profs. 
Yukio Yamaguchi and Teruyuki Nagamune for their help in the preparation of polypeptides.

\section{REFERENCES}

(1) Mithieux, S. M.; Weiss, A. S. Adv. Protein Chem. 2005, 70, 437461.

(2) Vrhovski, B.; Weiss, A. S. Eur. J. Biochem. 1998, 258, 1-18.

(3) Keeley, F. W.; Bellingham, C. M.; Woodhouse, K. A. Philos. Trans. R. Soc., B 2002, 357, 185-189.

(4) Wise, S. G.; Weiss, A. S. Int. J. Biochem. Cell Biol. 2009, 41, 494497.

(5) Bellingham, C. M.; Woodhouse, K. A.; Robson, P.; Rothstein, S. J.; Keeley, F. W. Biochim. Biophys. Acta 2001, 1550, 6-19.

(6) Tamburro, A. M.; Bochicchio, B.; Pepe, A. Biochemistry 2003, 42, $13347-13362$.

(7) Bochicchio, B.; Pepe, A. Chirality 2011, 23, 694-702.

(8) Pepe, A.; Guerra, D.; Bochicchio, B.; Quaglino, D.; Gheduzzi, D.; Pasquali-Ronchetti, I.; Tamburro, A. M. Matrix Biol. 2005, 24, 96109.

(9) Pepe, A.; Bochicchio, B.; Tamburro, A. M. Nanomedicine 2007, 2, 203-218.

(10) Bochicchio, B.; Pepe, A.; Flamia, R.; Lorusso, M.; Tamburro, A. M. Biomacromolecules 2007, 8, 3478-3486.

(11) Tamburro, A. M.; Pepe, A.; Bochicchio, B.; Quaglino, D.; Pasquali Ronchetti, I. J. Biol. Chem. 2005, 280, 2682-2690.

(12) Muiznieks, L. D.; Keeley, F. W. J. Biol. Chem. 2010, 285, 3977939789.

(13) Daamen, W. F.; Veerkamp, J. H.; van Hest, J. C. M.; van Kuppevelt, T. H. Biomaterials 2007, 28, 4378-4398.

(14) Lee, J.; Macosko, C. W.; Urry, D. W. Macromolecules 2001, 34, 5968-5974.

(15) Nowatzki, P. J.; Tirrell, D. A. Biomaterials 2004, 25, 1261-1267.

(16) Kim, W.; Chaikof, E. L. Adv. Drug Delivery Rev. 2010, 62, 14681478

(17) Chilkoti, A.; Christensen, T.; MacKay, J. A. Curr. Opin. Chem. Biol. 2006, 10, 652-657.

(18) Dreher, M. R.; Simnick, A. J.; Fischer, K.; Smith, R. J.; Patel, A.; Schmidt, M.; Chilkoti, A. J. Am. Chem. Soc. 2008, 130, 687-694.

(19) Zhang, K.; Diehl, M. R.; Tirrell, D. A. J. Am. Chem. Soc. 2005, 127, 10136-10137.

(20) Zhang, K.; Sugawara, A.; Tirrell, D. A. ChemBioChem 2009, 10, 2617-2619.

(21) Urry, D. W. Angew. Chem., Int. Ed. 1993, 32, 819-841.

(22) Urry, D. W. J. Phys. Chem. B 1997, 101, 11007-11028.

(23) Reguera, J.; Fahmi, A.; Moriarty, P.; Girotti, A.; RodriguezCabello, J. C. J. Am. Chem. Soc. 2004, 126, 13212-13213.

(24) McMillan, R. A.; Conticello, V. P. Macromolecules 2000, 33, 4809-4821.

(25) Di Zio, K.; Tirrell, D. A. Macromolecules 2003, 36, 1553-1558.

(26) Nagapudi, K.; Brinkman, W. T.; Thomas, B. S.; Park, J. O.; Srinivasarao, M.; Wright, E.; Conticello, V. P.; Chaikof, E. L. Biomaterials 2005, 26, 4695-4706.

(27) Sallach, R. E.; Cui, W.; Balderrama, F.; Martinez, A. W.; Wen, J.; Haller, C. A.; Taylor, J. V.; Wright, E. R.; Long, R. C., Jr.; Chaikof, E. L. Biomaterials 2010, 31, 779-791.

(28) Xia, X. X.; Xu, Q.; Hu, X.; Qin, G.; Kaplan, D. L. Biomacromolecules 2011, 12, 3844-3850.

(29) Flamia, R.; Salvi, A. M.; D’Alessio, L.; Castle, J. E.; Tamburro, A. M. Biomacromolecules 2007, 8, 128-138.

(30) del Mercato, L. L.; Maruccio, G.; Pompa, P. P.; Bochicchio, B.; Tamburro, A. M.; Cingolani, R.; Rinaldi, R. Biomacromolecules 2008, 9, 796-803.

(31) Rauscher, S.; Baud, S.; Miao, M.; Keeley, F. W.; Pomès, R. Structure 2006, 14, 1667-1676.

(32) Chow, D. C.; Dreher, M. R.; Trabbic-Carlson, K.; Chilkoti, A. Biotechnol. Prog. 2006, 22, 638-646.

(33) Tamburro, A. M. Nanomedicine 2009, 4, 469-487.

(34) Diehl, M. R.; Zhang, K.; Lee, H. J.; Tirrell, D. A. Science 2006, $311,1468-1471$.
(35) Urry, D. W.; Shaw, R. G.; Prasad, K. U. Biochem. Biophys. Res. Commun. 1985, 130, 50-57.

(36) Bellingham, C. M.; Lillie, M. A.; Gosline, J. M.; Wright, G. M.; Starcher, B. C.; Bailey, A. J.; Woodhouse, K. A.; Keeley, F. W. Biopolymers 2003, 70, 445-455.

(37) Kozel, B. A.; Rongish, B. J.; Czirok, A.; Zach, J.; Little, C. D.; Davis, E. C.; Knutsen, R. H.; Wagenseil, J. E.; Levy, M. A.; Mecham, R. P. J. Cell. Physiol. 2006, 207, 87-96.

(38) Bressan, G. M.; Pasquali-Ronchetti, I.; Fornieri, C.; Mattioli, F.; Castellani, I.; Volpin, D. J. Ultrastruct. Mol. Struct. Res. 1986, 94, 209216.

(39) Matsuura, K.; Hayashi, H.; Murasato, K.; Kimizuka, N. Chem. Commun. 2011, 47, 265-267.

(40) Ruan, L.; Zhang, H.; Luo, H.; Liu, J.; Tang, F.; Shi, Y.-K.; Zhao, X. Proc. Natl. Acad. Sci. U.S.A. 2009, 106, 5105-5110. 